Como citar este artículo en APA: Brito Rodríguez, S., Basualto Porra, L., Muñoz Vallejos, D. \& Reyes Ochoa, L. (2020). Teología transversal universitaria: claves formativas para los jóvenes de la educación superior.

Cuestiones Teológicas, 47 (107), 022-042. doi: http://doi.org/10.18566/cuete0.v47n107.a02

Fecha de recepción: 12 de noviembre de 2019 / Fecha de aceptación: 15 de enero de 2020

\title{
TEOLOGÍA TRANSVERSAL UNIVERSITARIA: CLAVES FORMATIVAS PARA LOS JÓVENES DE LA EDUCACIÓN SUPERIOR.
}

\author{
University Transversal Theology: Education Skills for Youth in Higher Education
}

\author{
Sonia Brito RodrígueZ ${ }^{2}$ \\ Lorena Basualto Porra ${ }^{3}$ \\ Doris MuÑoz VAlLeJos ${ }^{4}$ \\ Luis ReYes OCHOA ${ }^{5}$
}

\section{Resumen}

El Sínodo de los obispos sobre las/los jóvenes ha puesto de manifiesto la necesidad de revisar las realidades juveniles, además de proponer nuevos lenguajes formativos y evangelizadores. El artículo tiene el propósito de caracterizar una formación específica que es entregada por las universidades católicas a todos sus estudiantes en el área de la teología, para lo cual se consideran las voces de los jóvenes con respecto a sus creencias y experiencias en este campo formativo. El texto se fundamenta, conceptualmente, en el triduo magisterial fruto

\footnotetext{
Parte del artículo es producto de la sistematización de la asignatura "Cristianismo y hecho religioso" impartida en el Plan de formación integral de la Universidad Católica Silva Henríquez (UCSH), Santiago de Chile. La sistematización fue financiada por la Dirección de Docencia durante los años 2016 y 2017, constituyéndose en un proyecto interno de la Vicerrectoría Académica.

2 Doctora en Ciencias de la Educación, mención educación intercultural, Universidad de Santiago de Chile. Magíster en Educación Superior, Universidad Andrés Bello, Chile. Actualmente es académica permanente, Escuela de Trabajo Social, Facultad de Ciencias Sociales y Humanidades, Universidad Autónoma de Chile.

Correo electrónico: sonia.brito@uautonoma.cl

3 Profesora de Religión y Moral, Pontificia Universidad Católica de Valparaíso, Chile. Magíster en Teología Dogmática por la Pontificia Universidad Católica de Chile. Actualmente es Académica de la Universidad Católica Silva Henríquez, Chile. Correo electrónico: lbasualtop@ucsh.cl

4 Magíster en Educación Religiosa por la Universidad Católica Silva Henríquez, Chile. Licenciada en Ciencias de la Religión, Instituto Alfonsiano de Teología y Pastoral, Licenciada en Educación. Actualmente es Académica de la Universidad Católica Silva Henríquez, Chile. Investigadora del Centro Ecuménico Diego de Medellín.

Correo electrónico:dmunozv@ucsh.cl

5 Doctor en Didáctica y Organización Educativa, Universidad de Sevilla, Espańa. Profesor de Educación Religiosa para la Educación Media, IPES Blas Cañas. Actualmente es Académico de la Facultad de Educación Universidad Católica Silva Henríquez, Chile. Correo electrónico: 1reyeso@ucsh.cl
} 
del Sínodo de los jóvenes: Instrumentum laboris, Documento Final y Christus vivit, además de considerar las voces de las/los jóvenes con respecto a sus creencias y experiencias en este campo formativo, a través de dos instancias, a saber, Cuestionario on line de la Secretaría del Sínodo, contestada por las/los estudiantes de la Universidad Católica Silva Henríquez, Chile (UCSH), y un estudio realizado en la UCSH sobre las asignaturas teológicas. Se desarrollará una metodología de análisis de datos e información a ambos instrumentos, es decir, tanto de la encuesta de tipo cuantitativa como del estudio de orientación cualitativa. El texto se ordena en tres apartados, el primero referido a la encuesta on-line, el segundo al estudio de las asignaturas teológicas y, en el tercero, se concluye proponiendo una teología transversal universitaria cuyos pilares fundamentales son la dimensión antropológica de la búsqueda, la interreligiosidad, la antropodiversidad, la interdisciplinaridad, la trascendencia y la ética.

Palabras clave: Teología transversal; Experiencia religiosa; Joven; Estudiante universitario; Sínodo sobre los jóvenes.

\section{Abstract}

The Synod on Youth has highlighted the necessity to consider the realities of youth and to propose new formational and evangelization languages. The purpose of the article is to characterize a specific kind of education that is provided by catholic universities to their students in the area of theology. Bearing this in mind, it considers the ideas of the young regarding their beliefs and experiences within this educational sphere. The text is conceptually based on the magisterial triduum that came out of the Synod on Young People: Instrumentum Laboris, Final Document and Christus Vivit, in addition to considering the voices of the youth with respect to their beliefs and experiences in this formative field, through two instances, namely, an on-line questionnaire from the Secretariat of the Synod, answered by the students of the Universidad Católica Silva Henríquez, Chile (UCSH), and a study carried out at the UCSH on theological subjects. A methodology will be developed for the analysis of data and information for both instruments, that is, for both the quantitative survey and the qualitative oriented study. The text is arranged in three sections, the first referring to the online survey, the second to the study of the theological subjects and, in the third, it concludes by proposing a University Transversal Theology that should rest on the anthropological dimension of searching, interreligious dialogue, antropodiversity, interdisciplinarity, and ethics.

Key words: Transversal Theology; Religious Experience; Youth; University Students; Synod on young people.

\section{Introducción}

La formación teológica en el pueblo de Dios posee diversos niveles de profundización. Actualmente, la educación teológica impartida en los seminarios o facultades de Teología se realiza para los seminaristas, religiosos, algunas religiosas, diáconos y también para futuros profesores de religión o laicos interesados en el tema. Se podría afirmar que se trata de una teología disciplinar que en las universidades se oferta a través de programas de pregrado y postgrados. 
Junto a este modelo especializado de formación se encuentra una educación teológica pastoral que, principalmente, se imparte en las catequesis preparativas para los sacramentos, clases de religión y otras instancias de formación permanente, sobre todo para aquellos laicos que realizan algunos servicios de formación en sus comunidades. Pero existe otro tipo de educación teológica que, tradicionalmente, las universidades católicas entregan a todos sus estudiantes independiente de la carrera que cursen. Si bien durante muchos años se asumió que la teología para universitarios se debía realizar del mismo modo que la teología disciplinar, en gran medida porque los estudiantes que ingresaban a esas universidades tenían una definida opción de fe, actualmente se considera que esta formación debe poseer características propias, pues no es propiamente una teología disciplinar ni tampoco una teología pastoral. A esta teología para universitarios es la que se llama en el artículo como "teología transversal".

Ahora bien, en las últimas décadas, dicha formación teológica ha sido objeto de investigación en las universidades desde diferentes enfoques. Uno de ellos refiere a la formación teológica en las universidades católicas con respecto a su fundamento y misión. Como lo señala Aros (2016), las instituciones de educación superior, a la luz de las orientaciones magisteriales, buscan propiciar en el proceso de enseńanza-aprendizaje la apertura a la trascendencia de sus estudiantes, incorporando esta dimensión a su quehacer profesional. Es así como el autor desarrolla el tema desde el concepto de auto-comunicación de Karl Rahner como una forma de comprender la misión de la universidad, puesto que el ser humano "no elige ser trascendente, pues esta es una condición que le ha sido donada por el absolutamente trascendente, pero sí puede elegir desplegarse en su dimensión de trascendentalidad" (Rahner, s.f., 191) para colmar el espacio vacío del sentido de su existencia.

Otro enfoque busca indagar sobre el objetivo de los cursos de formación teológica, pues están demandadas por el hecho de contribuir a la "catolicidad de las universidades y a la formación identitaria que buscan brindar a sus estudiantes", lo cual lleva a preguntarse "¿qué se entiende por sello identitario, cómo se forma o se mide, cuáles son sus indicadores?”. (Cerda, 2017, 55). De allí la necesidad de establecer estudios metodológicos, didácticos y evaluativos que permitan establecer el mejor modo de enseńanza teológica y a la vez indagar sobre la pertinencia de las actividades curriculares en relación con los intereses y problemáticas propias de los jóvenes (Centro de Formación Teológica, 2014). Por su parte, según Brito y Basualto (2018) la implantación de un enfoque curricular por competencia ha permitido una opción por el desarrollo de habilidades en los estudiantes en desmedro de la ratio studiorum, como se concebía antiguamente la enseñanza de la teología, basada principalmente en la fundamentación racional de la fe.

Además, el tránsito en Occidente de la cristiandad hacia sociedades plurales ha producido un cambio de paradigma en la formación teológica centrada principalmente en la fe y costumbres del catolicismo. Estos aprendizajes se concebían necesarios para vivir en la sociedad de cristiandad; sin embargo, en una sociedad civil plural, donde la religión católica es una de las tradiciones religiosas presentes en el mundo que dialoga con otras religiones y otras creencias, las narrativas teológicas debieran ser distintas (González de Cardedal, 2016). En este sentido, según Arteaga (2002) la teología universitaria para no teólogos va adquiriendo la característica de transversalidad y diálogo con las distintas disciplinas universitarias, con el propósito de ser un aporte a la búsqueda de la verdad y al examen de la realidad. Además, la enseńanza de la teología ha estado asociada con la formación valórica de los estudiantes como un aporte a la ética profesional y a la formación personal (Basualto, Barahona, 2015; Farías, 2016; Muñoz, 2016). 
Hasta aquí se han descrito algunas aproximaciones a la forma en que se ha abordado el tema de la formación teológica para universitarios no teólogos. Sin embargo, cabe preguntarse por la voz de los jóvenes estudiantes con respecto a su formación teológica, pues como señala el Documento Final del Sínodo de los Obispos (2018b), "los jóvenes son uno de los 'lugares teológicos' en los que el Señor nos da a conocer algunas de sus expectativas y desafíos para construir el mañana” (n.64).

Es por este motivo que el artículo pretende proponer un lenguaje teológico para la formación universitaria a partir de los nuevos contextos juveniles y sociales, $y$, de ese modo, indicar algunas pistas para formular una teología transversal universitaria desde la realidad juvenil y sus demandas existenciales. Para desarrollar este objetivo se desarrollará una metodología de análisis a las respuestas de tipo cuantitativa del cuestionario on line contestada por los estudiantes de la Universidad Católica Silva Henríquez de Santiago de Chile (UCSH), la cual fue proporcionada por la Secretaría del Sínodo de los Obispos. Estos datos, que representan la voz de los estudiantes, se complementarán con un estudio realizado en la UCSH sobre las asignaturas teológicas que se ofertan para estudiantes de todas las carreras. Desde aquí se busca proporcionar algunas características de la teología transversal en la formación de estudiantes universitarios apoyadas en las orientaciones que entregan el triduo magisterial fruto del Sínodo de los jóvenes: Instrumentum laboris (2018a), Documento Final (2018b) y la Exhortación Apostólica Postsinodal, Christus vivit del Papa Francisco (2019).

Para llevar adelante este cometido, el artículo se ordena en tres apartados, el primero presentará un análisis de los resultados obtenidos en el Cuestionario on line para los jóvenes a cargo de la Secretaría del Sínodo, respondida por los estudiantes UCSH referida al tema de la fe y lo religioso. Posteriormente se presentarán los resultados sobre el estudio realizado por la UCSH sobre las asignaturas del plan teológico y, por último, se desplegarán algunos desafíos para la formación teológica transversal en contextos universitarios.

\section{Resultado y análisis de datos obtenidos en las preguntas focalizadas en lo religioso}

Durante el año 2018, la Universidad Católica Silva Henríquez (UCSH) se constituyó en una de las tres instituciones en Chile donde se aplicó el Cuestionario online para los jóvenes de la Secretaría del Sínodo. De este modo, la encuesta de tipo cuantitativa fue contestada por 149 jóvenes, en su mayoría mujeres (78,5\%), que durante el primer semestre del año 2018 cursaban alguna de las actividades curriculares del Plan de Formación Integral (PFI), plan que congrega a estudiantes de distintas carreras y facultades en diversos niveles de avance de sus planes de estudio (UCSH, 2016).

De esta manera, los datos provenientes de todo el mundo fueron considerados en el Instrumentum laboris de preparación al Sínodo de los Obispos y, según el Card. Baldisseri, Secretario General del Sínodo, el material recopilado a través de la encuesta online (citado en el documento como QoL) es inmenso y de gran valor, cumpliéndose el objetivo de escuchar a los jóvenes de todo el mundo (Sínodo de los Obispos, 2018a).

Ahora bien, el mismo Instrumentum laboris reconoce que "el QoL, como era previsible, vio una participación mayoritaria de jóvenes ya insertos en los circuitos eclesiales" (Sínodo de los Obispos, 2018a, n.64). En este sentido, la encuesta realizada en la UCSH tiene el valor de ser representativa de un sector de los 
jóvenes chilenos en un rango entre los 18 y 29 años de edad y que no están propiamente insertos en círculos eclesiales, pues son jóvenes universitarios de disímiles creencias, provenientes de diversas realidades y contextos.

Este primer apartado tiene por objetivo analizar las respuestas a las preguntas que se refieren, específicamente, a la dimensión de la fe, focalizándose en aquellos ítems que incluyen directamente la opinión de los jóvenes con respecto a su definición religiosa, prácticas religiosas e incidencia de la creencia religiosa en su vida.

\subsection{Definición religiosa}

El cuestionario permite identificar la definición religiosa de los jóvenes a partir del ítem 26 del cuestionario online, cuando se hace la pregunta "¿Cómo te defines en términos religiosos?”. A partir de las respuestas de los estudiantes de la UCSH se desprende que el 36\% se definen como católicos y un $5 \%$ evangélicos, por lo que se puede considerar que un $41 \%$ de los estudiantes se declaran cristianos.

Por su parte, el 28,2\% declara creer en Dios, pero no adhieren a ninguna religión institucionalizada. Por lo tanto, se puede considerar que existen nuevas búsquedas de Dios que trascienden los parámetros de las religiones clásicas y están lejos de la autoridad de los líderes religiosos.

También es importante considerar el porcentaje de estudiantes que no les interesa el tema, el cual alcanzó una cifra del 10\%. Por su parte, aquellos que se denominan agnósticos y ateos alcanzó un $8 \%$ en total, considerando que los jóvenes por lo general no comprenden bien la diferencia y asumen que ateo y agnóstico es lo mismo. De modo que existe un $18 \%$ de estudiantes para el cual el tema religioso no forma parte de su horizonte de cuestionamiento, o bien no tienen aproximación alguna al tema.

Estos datos obtenidos por los estudiantes UCSH no se alejan de la realidad nacional. El INJUV (2015), en una encuesta aplicada en 2015, señala que la disminución en la identificación con una religión disminuyó notablemente en un período de aproximadamente 20 años. Así, en 1997, el 91\% de los jóvenes manifestaban poseer una identificación religiosa, mientras que en 2015 disminuye a un $51 \%$. Por su parte, otras encuestas como Latinobarómetro (2018) señalan que el 45\% de los chilenos se declara católico, mientras que ADIMARK (2017) indica que en Chile el 50\% de los jóvenes entre 18 y 24 ańos declaran adherir al credo católico. A su vez, la encuesta CEP (2018) señala que la denominación católica en Chile es de un 55\%, la cual se desglosa por edades, donde el grupo etario entre los 18 y 34 ańos representa el $45 \%$ de los católicos y se declaran sin denominación (36\%).

Esta pregunta sobre la definición religiosa se complementa con otras referida a la identidad. En el ítem 2 de la encuesta online, se pide a los jóvenes subrayar tres aspectos de su identidad personal a elegir entre diez temáticas: política, estudios, tiempo libre, amigos, amor/partner, trabajo, país/nacionalidad, familia, religión, futuro. El 4\% indicó como un elemento de su identidad la religión, siendo la opción más elegida los temas del estudio y la familia, con un porcentaje de $79 \%$ y $76 \%$, respectivamente.. 
La pregunta 3 pide a los encuestados que si quieren explicar quiénes son elijan entre once alternativas ${ }^{6}$ en una jerarquización del uno al tres. Como primera opción, el 2,9\% responde que "les hablaría sobre mis convicciones religiosas", como segunda opción el $0 \%$ y como tercera opción el 3,5\%. Para tener un punto de referencias para la interpretación de estos resultados, las opciones más votadas son "les hablaría sobre las cosas que más me gustan" como primera opción en un 28,6\%, y como opción 2 y 3 "les hablaría sobre mis planes para el futuro" con un $25,7 \%$ y un $33,3 \%$, respectivamente.

Finalmente, en la pregunta 5 se consulta a los jóvenes "con respecto a tus padres te consideras" en una escala del 1 al 7: conservador, individualista, tolerante, interesado en el dinero, feliz, interesado en el ámbito religioso. En este último ítem, el 6\% se considera cercano a sus padres con respecto al tema de las creencias y un $37 \%$ se siente totalmente ajeno al traspaso de la fe religiosa que han hecho sus padres.

Ahora bien, esta realidad se puede relacionar con el tema del grado de confianza en las instituciones que se pregunta en el ítem 21 en una escala de 1 al 6 . Con respecto a las instituciones religiosas las respuestas oscilaron desde la mayor confianza con un $5,4 \%$ y la menor confianza con un $34 \%$. Cabe señalar que en medio de la crisis de las instituciones las mejores evaluadas en cuanto a la confianza son las ONG con un $13 \%$; las instituciones educativas con un $10 \%$, hospitales $8 \%$, organizaciones internacionales $6,7 \%$ y sindicatos $6 \%$. A la par con las instituciones religiosas están los Tribunales y los MCS. Aquellas que están bajo la institución religiosa son las multinacionales, las fuerzas armadas y policías con un 4,7\%; bancos $3,4 \%$; partidos políticos con un 2,7\%; administración local y empresarios $2 \%$ y gobierno nacional $1,3 \%$.

Es interesante que la encuesta considera también la consulta sobre la organización y movimientos en los cuales los jóvenes participan. La respuesta "sî" para el grupo religioso alcanzó el 18\% y la respuesta "no" un 75\%. Cabe señalar que el mayor porcentaje fue obtenido por las asociaciones deportivas con un $29 \%$, seguido de grupos artísticos y culturales con un 23\%. Todo el resto de las agrupaciones están bajo el grupo religioso: organizaciones feministas 17\%; organizaciones ecológicas/ambientalistas 16\%; voluntariado ONG y organización estudiantil, 13\%; organizaciones para la defensa de los derechos humanos 12\%; movimiento anti sistema 11\%; partido/movimiento político y sindicato $9 \%$. Esta misma pregunta la realiza el Instituto Nacional de la Juventud (INJUV, 2015), que señala que el 13\% de los jóvenes asumen que participa activamente, cifra que se acerca al $18 \%$ de la encuesta online.

\subsection{Prácticas religiosas}

La encuesta online hace la consulta sobre las actividades religiosas en las cuales el joven participa y con qué frecuencia las practica. Es así como la pregunta número 27 del cuestionario está construida bajo una escala de Likert con las opciones "muy a menudo", "a menudo", "raramente", "nunca" y "no contesta". El ítem considera diez tópicos referidos a las prácticas sacramentales de la confesión y la eucaristía, oración,

6 Las once alternativas se refieren a los siguientes temas: 1. "Explicaría quiénes son mis padres y qué trabajo hacen”; 2. "Diría en qué ciudad, barrio he vivido con mis padres"; 3. "Diría a qué escuela he asistido"; 4. "Diría a qué universidad he asistido"; 5. "Les explicaría quiénes son mis amigos"; 6. "Les hablaría sobre mis convicciones religiosas"; 7. "Les hablaría sobre mis ideas políticas"; 8. "Les hablaría sobre mis intereses principales"; 9. "Les hablaría sobre las cosas que más me gustan"; 10. "Les hablaría sobre los valores que guían mi vida"; 11 . "Les hablaría sobre mis planes para el futuro". 
lectura de la Biblia, participación en actividades pastorales de la universidad, parroquiales, misiones, acciones solidarias, peregrinaciones y reuniones.

Es interesante considerar que en las diez temáticas la opción "nunca” siempre fue mayoría. Si se analiza el detalle con respecto a las opciones "me confieso" la respuesta "nunca" alcanzó el 70\%; "voy a misa" 56\%; "rezar" 42\%; "leo la Biblia", 66\%; "recibo la comunión" 66\%; "participo en las actividades pastorales de la universidad", 83\%; "participo en las actividades de mi parroquia", 79\%; "participo en misiones", 79\%; "participo en acciones de solidaridad", 58\%; "voy a peregrinaciones/asisto a reuniones", $77 \%$.

Por otra parte, si se desglosan los datos de respuestas más afirmativas en las acepciones de "muy a menudo" y "a menudo", los porcentajes con respecto a la confesión es de un 5\%, "asistir a misa" de un 12\%, "rezar" 28\%, "leer la Biblia" 10\%, "comulgar" 12\%, "participación en actividades pastorales universitarias" 2,6\%, "actividades parroquiales" 6\%, "misiones" 2,7\%, "acciones solidarias" 16\%, "peregrinaciones o asistencias a reuniones" $7,4 \%$.

Es interesante analizar estas cifras en torno al 36\% de los que se consideran católicos, pues ninguna práctica religiosa alcanza ni siquiera el $30 \%$, por lo que se visualiza la desproporción entre aquellos que se declaran católicos y las prácticas que de ellas se derivan. Por su parte, llama la atención que la práctica religiosa más realizada por los jóvenes es la oración, y cabe la pregunta de a qué Dios se dirigen y cómo comprenden este diálogo.

\subsection{Incidencia de la creencia religiosa en la vida}

Los padres Sinodales también quisieron indagar sobre la incidencia de la creencia religiosa en la vida de los jóvenes. De esta manera, la pregunta 28 consulta: “¿En qué medida tu religión tiene un significado para cada uno de los siguientes aspectos de tu vida?" y pregunta por nueve ítems que, al igual que la pregunta 27, está elaborada a través de una escala de Likert con las opciones: "mucho", "bastante", "poco", "nada", "no contesta". Las temáticas que aborda se refieren a objetivos de vida como la relación de pareja, las formas en que vive la sexualidad, la elección de los amigos, la elección de la carrera universitaria, la orientación política, posiciones morales, acciones en la vida cotidiana y uso del tiempo libre.

$\mathrm{Al}$ revisar las respuestas de los estudiantes se puede visualizar que la respuesta "nada" es la que adquiere el mayor porcentaje en todos los ítems: objetivo de vida 35\%, pareja 49\%, sexualidad 57\%, amigos 55\%, carrera universitaria $56 \%$, política $65 \%$, moral $45 \%$, vida cotidiana $42 \%$, tiempo libre $55 \%$. Si se suman las alternativas mucho y bastante, aquella que alcanza un porcentaje más elevado son las referidas al tema de los objetivos de vida con un 32\% y los más disminuidos son los que se refieren a la forma en que se vive la sexualidad con un $12 \%$ y las orientaciones políticas que alcanza un $9 \%$.

Así mismo, el ítem 8a, también aborda la valoración de la religión en la vida cotidiana, consultando sobre las cualidades más importantes que ellos consideran que debería tener una persona. Dentro de un 
marco de trece posibilidades ${ }^{7}$ los estudiantes debían optar por seis, una de ellas es la que refiere a "fuertes convicciones religiosas", la que es elegida por un $10 \%$ de los encuestados; cabe señalar que la opción más votada fue la honestidad con un $83 \%$ de las preferencias. En el mismo ítem $8 \mathrm{a}$, se consulta sobre la "apertura hacia personas de cualquier credo y raza”, el cual obtiene una votación de un $48 \%$ de importancia como cualidad de una persona.

Por su parte, en la pregunta $8 \mathrm{~b}$, se hace la consulta inversa por las cualidades menos importantes donde las "fuertes convicciones religiosas" obtienen un 79\% de votación, confirmando el ítem $8 \mathrm{a}$, donde la opción religiosa no sería significativa en la identidad de una persona.

A su vez, la pregunta 9 entrega algunos datos sobre la incidencia de la creencia religiosa en la vida de los jóvenes, pues se consulta sobre "las personas o grupos que te han influenciado" en diversos ámbitos como son las elecciones educativas, objetivos de vida, confianza en mis capacidades, convicciones y compromisos religiosos, relaciones interpersonales, solidaridad y comprensión de los problemas del mundo. Entre los sujetos que presenta el ítem ${ }^{8}$, uno de ellos es la figura del sacerdote o persona religiosa. Así, para las "elecciones educativas", la figura del sacerdote o persona religiosa ha influido significativamente para un $1,3 \%$ de los encuestados, constituyéndose en la opción menos votada, mientras que la más alta votación la obtuvieron los padres con un 51\%. Con respecto al "objetivo de vida", la figura religiosa obtuvo un 9,4\%, volviendo a ser la más votada los padres con un 67\%; el único ítem donde el sacerdote o persona religiosa adquiere el mayor porcentaje es en la dimensión de convicciones y compromisos religiosos, con un $29 \%$.

Por su parte, la pregunta 29 consulta sobre los grados de importancia que el joven atribuye a ciertos objetivos de la vida9, entre ellos está el "sentirse más cerca de Dios". En una escala de 1 a 6, el 14\% se inclinó porque era un objetivo de gran importancia. Otros que se relacionan con el ámbito de la fe se refiere al ítem que considera "dar testimonio de mi fe" cuya votación fue de un $12 \%$ y aquel que establece como objetivo prioritario el "tener una vida espiritual" obtuvo un 16\%. Cabe señalar que aquel objetivo que obtuvo el mayor porcentaje fue "alcanzar mis objetivos con mis fuerzas" con un $71 \%$ y buscar la felicidad $69 \%$.

7 Las opciones son: 1. "Tolerancia con los demás, incluso con aquellos que son diferentes"; 2. "Fuertes convicciones religiosas"; 3. "Generosidad"; 4. "Empeño para alcanzar metas con tus propias fuerzas"; 5. "Honestidad"; 6. "Capacidad de amar"; 7. "Tener sentimientos fuertes hacia tu País"; 8. "Preferir vivir en el presente en lugar de hacer planes para el futuro"; 9. "Confianza"; 10. "Capacidad de relacionarse con los demás”; 11. "Apertura hacia personas de cualquier credo y raza"; 12. "Bienestar económico"; 13. "Capacidad de mantener un compromiso".

8 Entre las personas o grupos que presenta el ítem se considera los padres, otros familiares, maestros de escuela primaria/ secundaria, sacerdote o persona religiosa, amigos, compañero/a, profesor universitario, comunidad o grupo al que está afiliado y ninguno de los anteriores.

9 La pregunta versa de la siguiente manera: 1. Formar una familia; 2. Sentirse más cerca de Dios; 3. Alcanzar mis objetivos con mis fuerzas; 4. Contribuir a cambiar la sociedad; 5 . Ayudar a los pobres y a los necesitados; 6. Dar testimonio de mi fe; 7. Satisfacer las expectativas de mis padres sobre mi persona; 8 . La búsqueda de nuevas experiencias; 9. Tener una vida espiritual; 10. Llevar una vida acomodada; 11. Ser importante en un sector de la vida que elijo; 12. Ganar mucho dinero; 13. Ser ciudadano respetuoso y civil; 14. Hacer algo importante que deje una huella después de mí; 15. La búsqueda del placer; 16. La búsqueda de la felicidad. 
Finalmente, la pregunta 31 consulta sobre los proyectos de los jóvenes ${ }^{10}$ donde uno de los ítems es "unirme a un grupo religioso para fortalecer mi fe", el cual obtuvo una votación de un $0,7 \%$ siendo el más bajo, junto a entrar en política que obtuvo el mismo porcentaje, mientras que el ítem de encontrar un buen trabajo después de graduarme alcanza un $72 \%$, viajar a otras partes del mundo, $55 \%$ y formar una familia $46 \%$.

\section{Evaluación de asignaturas teológicas en la universidad}

La Universidad Católica Silva Henríquez, en su proceso de renovación curricular y hacia el tránsito de un currículum basado en competencias, renovó las actividades curriculares que se ofertaban para los estudiantes, entre ellos los correspondientes al Plan común universidad dentro de los cuales se encuentran las asignaturas teológicas. Incluso, como seńalan Brito y Reyes (2017), el plan cambia de nombre y se denomina Plan de Formación Integral para responder mejor al desafío de un currículum basado en competencias. En este nuevo plan, los estudiantes deben cursar una asignatura teológica eje que se denominó "Cristianismo y hecho religioso", la que tributa a la competencia genérica identitaria de reflexividad crítica ${ }^{11}$.

Cuando se implementa la actividad curricular se propone abordarla desde la metodología de investigación-acción, por lo que se levantó una sistematización con el propósito de desarrollar los aspectos epistemológicos teóricos, metodológicos, evaluativos y experienciales desplegados en la actividad curricular "Cristianismo y hecho religioso" (Muñoz y Basualto, 2017). Cabe precisar que, en el presente artículo, se expondrán solamente los resultados de dos objetivos, uno que implica indagar con los estudiantes los aportes de la actividad curricular en su formación profesional y, el otro, que buscaba analizar la metodología y aprendizajes de la actividad curricular. A partir del desarrollo de estos objetivos se pretende descubrir algunas pistas para levantar una teología transversal adecuada para el mundo universitario escuchando las voces de los estudiantes.

La metodología de trabajo de la investigación es cualitativa, y el grupo con el que se trabajó fueron los estudiantes de las cinco secciones de las carreras de psicología y trabajo social, lo que abarca un número de 180 estudiantes. Para alcanzar este propósito, se desplegaron tres técnicas, una pregunta abierta en el contexto de un coloquio sobre el tema de la trascendencia en la profesión: ¿Qué te aportan estas experiencias

10 Se trata de doce opciones de proyectos: 1. Encontrar un buen trabajo después de graduarme; 2 . Hacer una escuela de especialización y hacer una maestría o un doctorado; 3. Ganar mucho dinero; 4. Formar una familia; 5. Tener hijos; 6. Poseer una casa; 7. Pasar algunos años en un país pobre o en una región desfavorecida de mi País, trabajando para mejorar la vida de las personas en esa área; 8. Encontrar la manera de trabajar por una sociedad más justa y equitativa; 9. Unirme a un grupo religioso para fortalecer mi fe; 10. Viajar a otras partes del mundo; 11. Participar en la defensa de los derechos humanos, la paz, la ecología y otros movimientos sociales; 12. Entrar en política.

11 La competencia de reflexividad crítica versa como sigue: "Desarrollar su comprensión de la realidad sociocultural a través del discernimiento permanente de sus experiencias de aprendizaje, en el marco de una búsqueda de sentido de trascendencia para su vida personal y profesional. UCSH (2017). Guía procedimental. Competencias genéricas UCSH 2017. Santiago, Chile: UCSH, p. 19. 
de trascendencia en tu desarrollo personal y profesional ${ }^{12}$ Un focus group ${ }^{13}$ con estudiantes de diferentes secciones cuyas preguntas fueron: ¿Qué aprendizajes significativos hice durante el curso? ¿De qué modo impactan las creencias en mi desarrollo profesional? ¿Qué sugerencias haría para este curso? Y, por último, una encuesta online ${ }^{14}$, donde se hicieron las mismas preguntas que en el focus group.

A continuación, se presentan los resultados ordenados en tres apartados, a saber: aprendizajes significativos, aportes de la actividad curricular en su formación personal y profesional y propuestas de mejora.

\subsection{Aprendizajes significativos}

En cuanto a los aprendizajes significativos, los estudiantes señalan que el planteamiento del curso les permitió enriquecerse, pues ensancharon sus horizontes con respecto a la visión de Dios, las creencias, las religiones y la dimensión social de esta. De este modo, con el pasar del semestre, cayeron los prejuicios y pudieron valorar el curso en sí mismo. Al respecto, señalan:

Llegué al curso con la idea de que solo nos hablarían y explicarían sobre una religión, pero me fui dando cuenta de que se trataba de como las diferentes religiones impactan en nuestra sociedad la mayoría del tiempo de forma positiva, creo que ese fue el mayor aprendizaje (de forma generalizada) que tuve del curso (E17, encuesta).

Yo creo que el curso nos sirvió para darnos cuenta qué significa Dios para las distintas religiones (...) yo creo que nos sirvió mucho para enriquecernos con conocimientos nuevos, porque nunca nos introdujeron en el colegio otra religión, entonces yo creo que gracias a las presentaciones que hicieron nuestros compañeros, nosotros pudimos criticar o profundizar más. (E2, focus).

Dentro de los aprendizajes de los estudiantes se puede apreciar que logran captar el vínculo entre religión y cultura, además de las implicancias que esto tiene en los distintos ámbitos de la vida. En este sentido, distinguen el impacto de una práctica religiosa en la vida cotidiana de las personas y, a partir de ello, reconocen la diversidad humana a partir de las creencias que existen. Para ellos, no son mejores ni peores cada una de las creencias, sino distintas. Por ello dicen:

Qué importante es para nosotros saber que somos diferentes, que cada uno piensa de una manera diferente, y que vive la vida de manera diferente y es increíble cómo uno se da cuenta de que otras personas viven algo muy desigual a lo que yo puedo vivir, por ejemplo, yo me puedo levantar en la mańana, lavarme los dientes y vivir una vida cotidiana, pero para otra persona, no sé, levantarse a meditar o levantarse a cantar, esa es una vida cotidiana para él. Entonces, realmente, lo que yo creo que me marcó es esta asignatura fue aprender que somos todos diferentes, todos buscamos algo, pero, realmente uno piensa que uno tiene la razón. Piensa que lo que uno vive es lo que realmente y no es así, porque somos todos con distintas formas de pensar y la

12 En los resultados se le asigna la nomenclatura: En, coloquio (estudiante, número asignado, coloquio)

13 En los resultados se le asigna la nomenclatura: En, focus (estudiante, número asignado, focus)

14 En los resultados se le asigna la nomenclatura: En, encuesta (estudiante, número asignado, encuesta) 
creencia realmente impacta muy fuerte, o sea, si yo creo en los monoteístas o en una religión politeísta, impacta en mi vida realmente de una manera súper fuerte, o sea, depende totalmente de mi día a día. (E6, focus).

Otro aprendizaje significativo fue descubrir el impacto de las creencias y lo religioso en la transformación social y política que datan de tiempos inmemoriales en las diferentes culturas. A su vez pudieron aplicar esta dimensión a la experiencia religiosa católica y cristiana en Chile y América Latina, a partir de la vida comprometida con la justicia social del cardenal Raúl Silva Henríquez y de monseñor Oscar Romero. De esta manera plantean que:

Las religiones en la sociedad han acompañado durante todo el desarrollo del hombre hasta la actualidad, y ha marcado de manera profunda su vida, sus costumbres, sus creencias, su modo de ver el mundo en el que vive y de organizar la comunidad en la que se asienta. (E13, encuesta).

También quiero resaltar, que hablé un poco de la política y la religión en una clase donde se veía cómo la sociedad, y obviamente el gobierno de ese entonces, manipulaba a toda la gente a su favor, y no dejaba que nadie, ni siquiera una figura religiosa pudiera interponerse en eso (...) por ejemplo, creo que había el caso de un cura en El Salvador, creo que era (¿Monseñor Romero?), claro él, entonces, él a través de Dios, a través de su propio plan, de su propia visión quería que su pueblo se diera cuenta de todas las injusticias que estaban ocurriendo. Eso también se puede llevar al caso de Chile, que acá también eso pasó con la dictadura militar, que mucha gente se salvó gracias -en parte- a figuras religiosas y gente que realmente luchó por la gente, se levantaba cada día por eso. (E4, focus).

Como se puede apreciar, la misión que ha jugado la religión en la sociedad es valorada por los estudiantes, ya que reconocen que la Iglesia Católica ha caminado en la historia del pueblo chileno y que va también de la mano de las causas sociales, destacándose el rol de la Vicaría de la Solidaridad en tiempos de dictadura. También, señalan que es necesario vivirla de un modo más cercano y humano poniendo menos énfasis en una divinidad lejana. En esta misma línea, se agrega que la religión tiene mucho que decir a la sociedad y en ese sentido se reconoce el aporte del cardenal Raúl Silva en tiempos de dictadura, "a mí me cuestionaba mucho el video ese de cuando el cardenal se enfrentaba al general Pinochet y decía si es necesario esconder gente debajo de mi cama, lo voy a hacer..." (E7, focus). Por ello, los estudiantes son capaces de realizar un análisis crítico donde se cuestiona el silencio y la lejanía actual de la Iglesia Católica frente a las demandas de justicia y de algunos derechos que afectan la vida de muchos jóvenes. A modo de ejemplo un estudiante señaló:

Yo me cuestiono la iglesia de la dictadura y la iglesia de hoy día, cuando no escucho a nadie de la iglesia hablar sobre temas de educación, cuando los grandes colegios católicos de Chile son los mejores, los más ricos, con una educación privilegiada y no son capaces de sacar la voz cuando hablamos temas de calidad, y cuando hablamos temas de gratuidad, cuando la religión solamente se escandaliza cuando hablamos de aborto o cuando hablamos de unión civil... yo creo que la religión ha perdido un poco su foco en el sentido de que tienen que hacer una opción por el amor, por el amar al otro, devolver el amor, devolver alegría, devolver esperanza de vivir y de confiar también en esta sociedad, que la conformamos todos. (E4, Focus).

Un aprendizaje actitudinal importante del proceso, es que se logra explicitar el respeto a la persona y sus creencias, es por eso que ellos mismo sacan por conclusión la necesidad de ser cuidadosos en los juicios 
a priori. De esta manera, los estudiantes hacen la síntesis que todas las religiones y creencias pueden ser un aporte no solo para la vida personal, sino también para la vida social. Al respecto señalan:

También hay que ser súper cuidadosos con los juicios que hacen de las otras religiones, muchas veces cuando hacemos un juicio negativo en el catolicismo tiene mucho que criticarse de verdad, y muchas veces es a priori, no con algunas experiencias de comunidad o unas experiencias de vida, sino que totalmente por lo que se escucha, por lo que vive, pero no hay una... un caminar dentro de una comunidad cristiana, que esté ya formado. Y si pasa eso, yo creo que la perspectiva de la religiosidad, o del cristianismo, del catolicismo es completamente distinta. (E3, focus)

Al mismo tiempo, los estudiantes reconocen el rol que cumple cada persona, toda vez que ha experimentado un cambio en su vida a partir de una experiencia religiosa y desde allí, cambia la actitud con respecto a los demás. Esto se aprecia en las palabras de esta estudiante;

También se puede ver reflejado, o sea no tan solo el rol que cumple la religión en la sociedad, sino que cada uno de nosotros, cada persona, hace y construye todo ese rol social. Esto se explica porque ella plantea que para algunas personas es tan importante el impacto de la religión en las personas que, efectivamente impacta la vida personal del creyente y su entorno. De ahí esta afirmación; por ejemplo (...) de mucha gente que se da cuenta de que Dios puede cambiar su vida y que también puede cambiar la de los demás. (E6, focus)

Se valora también el papel de la religión católica en la formación moral y ética que, desde la infancia a través de la educación familiar, inculcó valores que han quedado grabados en la memoria como un mandato poderoso. El imperativo ético de que la vida es sagrada se reconoce como un valor fundamental para ser una persona que busca el bien común y la justicia social. En ese sentido, ser una buena persona es una enseñanza que quedó grabada en ellos, pese a que hoy no practiquen una religión determinada. Esto se expresa cuando un estudiante señala:

...yo creo que el rol (de las religiones) es... muy de ética-moral y por eso vimos lo del bien común y todo eso... por los dogmas que tiene del no robarás, no matarás, yo creo que fueron los primeros valores, o lo primero que nosotros aprendimos cuando chicos, que robar es malo, que la familia está primero... esos valores como que en el fondo forman a la persona, pare ser una buena persona que vela por la justicia social, por el bien común (E5, focus)

Otro rol que se atribuye a la religión, según los estudiantes, es la de llenar el vacío existencial que no se satisface con las relaciones humanas ni con los pasatiempos. Al respecto seńalan:

...yo creo que la religión en sí busca satisfacer una necesidad que está dentro de cada uno de nosotros... y muchos vacíos en el corazón, en el alma, en cualquier parte esos vacíos que quizás no los puede llenar un grupo de música o mi familia, pero si quizás una religión sí las puede llenar (E1, focus)

yo lo busco (llenar el vacío) por medio de quizá no una religión (...) yo creo que cada uno vive, como una creencia en sí mismo, pero no necesariamente tiene que vivir una religión (E7, focus) 
Dios está dentro de uno mismo, y uno es como el encargado de encontrarlo y hacerlo despertar (...) yo creo que al fin y al cabo la religión es como un ancla dentro tuyo y te hace centrarte igual, que te hace pensar de una forma distinta (E4, focus)

Como se puede apreciar, los estudiantes plantearon la diferencia entre religión y creencia, pues algunos afirman que es posible llenar el vacío con una creencia en Dios y no necesariamente siendo parte de una religión institucionalizada. En este sentido, se acentúa el aspecto subjetivo de la religión; sin embargo, reconocen la importancia de la adhesión a una creencia, la cual permite una cosmovisión distinta, a veces difícil de comprender para un no creyente.

\subsection{Aportes de la actividad curricular en su formación personal y profesional}

Analizando las respuestas de los estudiantes, según Muñoz y Basualto (2017) se puede visualizar su diversidad con respecto al aporte de la actividad curricular en la formación personal y profesional, que va desde el nulo impacto en lo profesional hasta la visión que la elección de la carrera estuvo marcada por la vivencia del cristianismo, pasando por una valoración de las religiones en su aporte a la humanidad que entra en diálogo con diversas creencias y ámbitos. Al respecto señalan los estudiantes:

...como dije anteriormente, yo no creo mucho, entonces a mí las creencias nunca me han afectado en lo profesional (E5, encuesta)

Mis bases de la religión están en el cristianismo católico y estoy estudiando trabajo social. Mis bases están en el querer ayudar, en el amor al otro por sobre todas las cosas (...) mi religión me ayudó para donde estoy ahora (E1, focus)

Demasiados aprendizajes fueron significativos durante el curso. Me quedo principalmente con las autorreflexiones que teníamos con los temas tocados, algunos tan básicos como el amor y otros tan intrigantes como la muerte. Conocimos diferentes religiones que logran convivir en este mundo de una u otra forma pese a sus diferencias y además aprendimos y aplicamos valores que nos acompańaran no solo en la carrera, si no en nuestra vida general. (E9, encuesta)

En este mismo sentido, se reconoce en los valores cristianos un aporte a la humanización, y desde ahí a descubrir la creencia como un valor agregado en tanto esté vinculado a una práctica concreta que ayuda al desarrollo de la ética profesional. En este sentido, los estudiantes señalan:

(mi profesión, trabajo social) quiere aportar a devolver el poder que tiene el individuo de transformar su vida, donde él es libre de querer decidir cómo la va a transformar...y devolverle la dignidad para transformarlo en un sujeto de derechos, lo que tiene que garantizar cada Estado. Entonces el amor y la religión, y los valores aportan porque humanizan desde el cristianismo (E1, focus)

Las creencias impactan en mi desarrollo profesional en que mediante ella obtenemos valores los que me ayudarán a seguir mi camino de buen modo (E23, encuesta) 
Las creencias impactan de una manera positiva a mi desarrollo profesional ya que ayuda a mantener nuestros principios y valores, para así tener una práctica que sea ética. (E5, encuesta)

También se expresa la creencia cristiana de que Dios es amor, y si no se tiene amor de nada vale hacer lo que se haga. En esta relación, todo lo que se hace con amor refleja a Dios porque Dios es amor, lo que permite una práctica profesional que se comprende más desde la entrega al prójimo. Al respecto señalan los estudiantes:

Yo creo que el amor es fundamental. Llevándolo al ámbito del cristianismo o de Dios, Dios mismo dice que si no tengo amor de nada me vale, o que también Dios es amor, por lo tanto, yo creo en donde nosotros hacemos nuestros actos, sin querer, también reflejamos a Dios, aunque no queramos, porque Dios es amor (E3, focus)

... (las religiones) ayudan a obtener una visión menos materialista de la realidad, pues cuando se trabaja por vocación, motivación y ayudando a los demás, no principalmente por dinero, me siento bien conmigo misma (E17, encuesta)

Finalmente, desde la escucha de testimonios de los profesionales de su área, en relación con la dimensión trascendente de su profesión, para los estudiantes lo fundamental en el desarrollo profesional es el amor como motor e impulso del actuar, más allá de los aprendizajes teóricos y metodológicos y más allá de la mera palabrería. Es decir, se reconoce el amor como aquello que anima e impulsa a otros a transformar la vida y recuperar la dignidad, lo cual les entrega un horizonte que va más allá del bien extrínseco de la profesión y situarse más bien desde la dimensión intrínseca.

Desde mi perspectiva, estas experiencias de trascendencia aportan una mirada diferente; una forma de ver al otro más allá de un paciente; un ser humano que requiere de ayuda y amor. Desde lo personal, pienso que trascender también es seguir, ser fuerte, lograr reponerme de aquellas cosas difíciles. Trascender en mi futuro ejercicio profesional me da esperanza, de un mundo mejor, de ser una mejor persona (E32, coloquio)

Las experiencias compartidas me ayudaron a comprender que:

1. No hay que trabajar solo por dinero, sino que para ayudar al prójimo 2. No necesariamente hay que ser creyente o católico para trascender. 3. Trascender en la profesión nos hace mejores personas. (E27, coloquio)

El sentido de la trascendencia entrega un sentido a mi desarrollo profesional y personal. Sentido que está directamente relacionado con el amor, que se les entrega a los otros y uno mismo, un sentido más de vocación que de profesión. A opinión personalmente la transcendencia en el trabajo social se ve reflejado en la justicia social, bien común y sobre todo en el amar. (E34, coloquio)

Es interesante visualizar que estas reflexiones de los jóvenes provienen de escuchar a sus propios académicos de la disciplina que realizaron el vínculo entre su saber y la dimensión trascendente del ser humano, incluyendo en este aspecto sus creencias en relación con la vivencia de su profesión. 


\subsection{Propuestas de mejora}

Los estudiantes reconocen que, al iniciar la actividad curricular, muchos de sus compañeros y ellos mismos se encontraban desmotivados, pues lo religioso no es una temática de gran interés. Sin embargo, a medida que van realizando el curso se percatan de que hay temáticas que tienen sentido y que el curso puede resultar mucho más interesante de lo que habían imaginado. En esta línea, las sugerencias de mejora son variadas y van desde la metodología en el aula, la innovación y las didácticas, entre otras.

Para el desarrollo de la actividad académica, aunque se considera que las clases son atractivas, los estudiantes aprecian la dificultad que es encantar a aquellos que vienen sin ningún interés a la actividad curricular. Al respecto recomiendan:

Yo creo que es súper difícil enseñar algo que a lo mejor la otra persona no quiere aprender, o que no quiere aceptar, entonces, hay métodos, claro que sí, pero yo creo que el método tradicional de cómo hacer clases estaría fallando en este caso, porque estar a lo mejor la profesora o el profesor encargado del curso adelante, y hablando sobre a lo mejor Jesús y cosas así, la persona que no le gusta y que no quiere entender no va a entender y no va a querer entender y se va a poner en esa postura. Yo creo que a lo mejor es hacerlo llegar de otra forma, de relacionarlo con actividades diarias a lo mejor, de hacer como cosas dinámicas, y, al fin y al cabo, tomarle un sentido, relacionarlo con lo que se quiere enseñar, yo creo que sería como una buena solución (E2, focus)

En cuanto a las sugerencias para mejorar los aprendizajes, los estudiantes plantearon la necesidad de aumentar el trabajo en terreno, por cuanto este es de alta participación y es muy valorada la forma de aprender y construir aprendizajes a partir de otro lugar pedagógico. Por ejemplo, visitar templos, mezquitas y afines. También se ve necesario incorporar en la actividad curricular de aula la posibilidad de contar con testimonios de personas de otras religiones que den cuenta de la diversidad religiosa que se expresa en la actualidad y que se conoce, mayormente, a través de textos u otros materiales. Al respecto señalan:

Yo me daba cuenta que había gente que cuando hablaban de otras religiones, se impactaba y decía oh, yo no sabía que era esto, yo no sabía que hacían esto, y volviendo al tema también de clases más dinámicas, yo creo que tal vez, nos faltaron como más salidas, no sé, yo creo que por ejemplo, haber vivido una reunión, o haber hablado con un budista, por ejemplo, haber ido hasta un templo budista o yo creo que esas cosas hubieran marcado más que una clase donde solamente se habló como lo general o lo teórico de una religión, yo creo que si muchos de los compañeros hubieran vivido una misa u otro rito de otra religión, hubiera impactado un poco más o hecho la clase, como decía, con más dinámica. (E3, focus)

Las sugerencias que haría yo, para el curso de Cristianismo, es que se podrían hacer más actividades o más salidas, no solo estar en el aula y pasar ppt, también sería bueno que sacaran más a los alumnos para que aprendan de las religiones. (E28, encuesta)

Las sugerencias que tengo es que las actividades sean más didácticas (...) debiera haber más trabajos grupales donde se pueda compartir con el otro. (E36, encuesta) 
En el contexto de esta pregunta, se pueden apreciar sugerencias que necesariamente relacionan la enseñanza de la teología con el aporte de las ciencias pedagógicas en lo que se refiere a la metodología y didácticas. Además, se ve la necesidad de relacionar la teoría con la realidad y sobre todo con los sujetos que optan por una experiencia religiosa.

\section{Desafíos para la formación teológica transversal en contextos universitarios}

Este apartado busca caracterizar una teología transversal para los estudiantes universitarios a partir de los resultados del cuestionario online de la Secretaría del Sínodo y la investigación del curso teológico de la UCSH.

La encuesta muestra que la identificación de los estudiantes con el credo católico tiende a la baja. Por lo tanto, uno de los primeros aspectos a considerar es que, en el aula universitaria, menos de la mitad de los jóvenes se declaran católicos. A su vez, desde las encuestas se puede desprender que las prácticas religiosas propias de alguien que opta por la fe católica se desarrollan en un porcentaje muy escaso, por eso el promedio de los católicos practicantes es de alrededor de un 10\%. Si se considera el número de estudiantes quiere decir que de cuarenta estudiantes solo veinte son católicos y solo dos se consideran católicos practicantes que les puede interesar el saber teológico como creyente, y el resto puede tener otras motivaciones religiosas, espirituales o ningún interés por la disciplina.

Ahora bien, estos datos muestran un cambio en la sociedad chilena que se viene observando desde los ańos noventa y se incrementa desde la última década, debido a la crisis que atraviesa la Iglesia Católica que ha generado, a su vez, una crisis de credibilidad. Como señalan González y Basualto (2019), "las causas de esta situación provienen de una iglesia-institución distanciada de la humanidad y de la persona de Cristo, además de una praxis escandalosa en materia sexual y de poder” (González y Basualto, 2019, 15).

En este contexto, surge una nueva religiosidad donde la persona cree en Dios y busca formas de comunicarse con él, germinando nuevas espiritualidades que no necesariamente se plasman en una institución religiosa tradicional. Como señalan los jóvenes chilenos de la Pastoral juvenil, esta nueva generación presenta "un desencuentro entre creencia y adherencia formal a la vida eclesial" (Comisión Nacional de Pastoral Juvenil, 2018, 12). De esta manera, para los jóvenes la dimensión religiosa se vive de forma privada más que comunitaria. Así, por ejemplo, en la encuesta CEP (2018) la afirmación "tengo mi propia forma de conectarme con Dios, sin iglesias ni servicios religiosos" obtuvo un acuerdo de 65\%, mientras el resto de las respuestas se encontraban dentro del margen de lo institucional. Por tanto, se puede desprender que continúa habiendo una búsqueda de lo religioso, incluso el Sínodo de los Obispos (2018a) plantea que en la postmodernidad hay un regreso a lo religioso, pero más bien se debería señalar que se trata de nuevas búsquedas más holísticas y con más capacidad de valoración a diversas experiencias de creencias. Como señala el Instrumentum Laboris: "muchos jóvenes afirman que están buscando el sentido de la vida, que siguen los ideales, buscan una espiritualidad y una propia fe personal, pero solo pocas veces recurren a la Iglesia" (Sínodo de los Obispos, 2018a, n.63). 
Con estos datos se podría desprender la primera característica de la teología transversal en cuanto ser una teología de la búsqueda, pues independientemente del credo abrazado por los jóvenes estudiantes, todos buscan una espiritualidad, un sentido existencial, una vida con valores o la trascendencia. Por lo tanto, la teología transversal, más que explicitar verdades dogmáticas estáticas, trata de abrir el diálogo hacia una búsqueda de la verdad.

Desde aquí se desprende una segunda característica fundamental de esta teología transversal: necesariamente debe ser interreligiosa. Este aspecto es altamente valorado por los estudiantes en cuanto a respetar todas las creencias y descubrir sus riquezas. De hecho, en el curso de cristianismo y hecho religioso, los alumnos agradecen conocer otras religiones y, así, hacer justicia en su formación, pues siempre les habían enseñado solo la religión católica. De allí, que se critica una formación monotemática y hegemónica donde el catolicismo se impone como creencia y se instala como el único discurso establecido capaz de responder al vacío existencial.

Se trata, por tanto, de desplegar una teología transversal desde la dimensión del diálogo interreligioso y en el contexto de la narrativa de la interculturalidad, aceptando de esta manera el desafío que instala Fornet-Betancourt (2006) cuando plantea la necesidad de renovar la teología con base en el diálogo entre las culturas, la diversidad y la pluralidad, y poniendo en cuestión su normalidad cultural y discursiva. De esta manera, la teología católica que ha sido predominante en Occidente necesita "complementar su capacidad de hablar de Dios interculturalmente con el desarrollo de un lenguaje que libere su discurso sobre Dios de los límites de su religión de procedencia por la interacción con el espíritu de Dios en el otro" (Fornet-Betancourt, 2006, 57). También, el Sínodo de los Obispos (2018b), después de escuchar a miles de jóvenes de todo el mundo, presenta la importancia que ellos dan al diálogo interreligioso cuando afirma que "los jóvenes generalmente muestran una apertura espontánea ante la diversidad, que los hace estar atentos a las temáticas de la paz, la inclusión y el diálogo entre culturas y religiones" (n. 45). En este sentido, la teología transversal se instala más allá del ecumenismo o diálogo interreligioso, asumiendo los desafíos de la interculturalidad, ampliando los campos semánticos, resignificando el concepto de inculturación del evangelio y, en definitiva, más allá de concebir a la Iglesia Católica como única tabla de salvación, por lo que es imperioso renovar la eclesiología.

Ahora bien, la interreligiosidad necesita de una nueva dimensión antropológica que conviva con las diferencias personales, por lo que la teología transversal necesita construirse desde la antropodiversidad (Aguiló, 2010). Esta tercera característica, en la que debiera fundamentarse la teología transversal, se hace presente en los estudiantes universitarios que viven diariamente relaciones interpersonales con jóvenes que poseen diversos intereses, como se pudo visualizar en los primeros apartados. Ellos se orientan principalmente a los ámbitos de los estudios, el trabajo, la familia, las amistades, las relaciones de pareja y las redes sociales, por tanto, son temáticas que se deben priorizar en ese tipo de teología. Junto a estos intereses, los estudiantes se relacionan con otros jóvenes que poseen diversas opciones con respecto al género, por lo que asumen con naturalidad las diferencias, pues están viviendo un cambio generacional donde se aceptan naturalmente nuevas femineidades y masculinidades (Sínodo de los Obispos, 2018b). Al mismo tiempo, al ser la teología transversal universitaria una narrativa especialmente para los jóvenes, ellos deberían convertirse en el lugar teológico por excelencia. Por tanto, sería más correcto señalar que se trata de una teología con los jóvenes y no para los jóvenes, ya que sus intereses y opciones debieran ser prioridad para esta teología, valorando así a todos y todas las jóvenes. De manera que la teología transversal 
no puede formar estereotipos sino, por el contrario, nutrirse de la diversidad y crear espacios de alteridad, espacios que los jóvenes aprecian cuando realizan su evaluación de la asignatura teológica.

Una cuarta característica de esta teología transversal se relaciona con el ámbito de la carrera profesional, pues como señala la encuesta online este ámbito de la vida del joven adquiere un lugar muy importante. Por eso, esta teología en contextos universitarios, necesariamente, debe ser interdisciplinar. Solo de este modo puede relacionarse con los saberes que interesan a los jóvenes, de lo contrario se experimenta en la formación universitaria una dislocación de saberes que permanecen totalmente aislados. De allí la necesidad de construir lenguajes comunes con otras áreas disciplinares de la universidad para así ir construyendo una teología interdisciplinar con las diferentes escuelas, de modo que el académico que desarrolle este tipo de teología pueda propiciar un diálogo fecundo en el aula. En definitiva, se trata de superar la desmotivación inicial que señalaban los estudiantes al cursar este tipo de asignaturas porque estiman que están totalmente alejados de su formación profesional.

Por otra parte, como señala la encuesta online, los jóvenes viven su vida desde el prisma de la autonomía y, por lo tanto, las decisiones que toman los jóvenes no se ven iluminadas desde la fe cristiana; sin embargo, desde la evaluación de la actividad curricular, es posible reconocer que en todas estas dimensiones vitales se entrecruzan una serie de creencias y valores donde los jóvenes experimentan su ser trascendente. Así, la trascendencia se constituye en la quinta característica de la teología transversal, al considerarse como un constitutivo antropológico que busca ir más allá de la inmanencia como responder las preguntas existenciales, la experiencia de la apertura a Dios y servir a los otros. En este sentido, si bien el ejercicio profesional posee un bien externo, los estudiantes consideran que el sentido verdadero está en el bien interno de la profesión basado en el amor al otro, la búsqueda del bien común y la justicia. En definitiva, señalaban los estudiantes en el coloquio, se trata de descubrir el amor como principio fundamental de la vida donde convergen las distintas creencias teístas y no teístas.

Desde esta visión de la trascendencia, la teología transversal encuentra su sexta característica en la dimensión ética, perspectiva que necesita considerar las diferentes creencias para emigrar de la esfera privada al ámbito de lo público y, así, reflexionar sobre su constatación práctica en la vida diaria y de esa manera transformen, positivamente, las esferas culturales y socio-políticas. Como señala el Papa Francisco (2019), "los universitarios pueden unirse de manera interdisciplinar para aplicar su saber a la resolución de problemas sociales, y en esta tarea pueden trabajar codo a codo con jóvenes de otras Iglesias o de otras religiones" (n.172).

En este mismo sentido, los estudiantes aprecian el legado valórico de las religiones en la construcción histórica de las sociedades, encarnadas en algunos personajes que desde sus convicciones profundas han sabido dejar una huella en la humanidad, a través de la lucha por la dignidad y por los derechos fundamentales de la persona. Al mismo tiempo, los jóvenes reconocen la educación valórica de sus familias, que nacen de creencias religiosas y que han sido traspasadas a ellos, aprehendidas y acogidas, de modo de hacer el proceso desde la heteronomía a la autonomía.

En síntesis, una teología transversal para universitarios posee su propio lugar teológico en los jóvenes, tiene la característica de ser una teología de la búsqueda, interreligiosa, antropodiversa, interdisciplinar, trascendente y ética, cuya metodología se inserta en el amplio campo de las metodologías inductivas. Pues, 
como señalan los jóvenes estudiantes, la enseñanza de esta teología debiera ser in situ, es decir, debe ser inductiva porque de esa manera se propicia la búsqueda, se valora la diversidad y se amplían los horizontes.

\section{Conclusión}

La situación de la Iglesia chilena es grave, como lo demuestran las cifras y el sentir de los jóvenes; por lo tanto, es necesario enfrentar esta situación con valentía pues, de lo contrario, la Iglesia chilena del siglo XXI pasará a la historia como aquella que les robó a los jóvenes la fe y la posibilidad de soñar. En este sentido, la tarea de reconstruir la Iglesia como pueblo de Dios se torna un imperativo de esta generación que no puede distraerse de esta misión cuya única respuesta se encuentra en la búsqueda de la alegría y de la santidad (Francisco, 2018b). La teología, en tanto narrativa de Dios y los seres humanos, necesita renovarse al ser interpelada por narrativas contemporáneas como el feminismo, la perspectiva de género, la interculturalidad, el clericalismo, la mujer, la ecología, entre otros.

Las universidades católicas, como espacios de intercambio de saberes entre las cuales se encuentra la teología, necesita plantearse las características que debería tener la teología en contextos universitarios. Es por este motivo que el artículo recoge el parecer de los jóvenes desde su posición ante la fe católica y desde la experiencia como estudiantes de una asignatura teológica del Plan de formación integral para responder a este interrogante.

Desde la voz de los estudiantes se desprenden algunas claves formativas para los jóvenes de la educación superior, claves que los autores han propuesto denominar teología transversal universitaria y cuyas características son: dimensión de la búsqueda interreligiosa, antropodiversa, interdisciplinar, trascendente y ética.

Así, el trabajo académico del teólogo o teóloga formador de los jóvenes estudiantes debería ser el trabajar estas dimensiones, las cuales están presentes en las diferentes temáticas abordadas en los cursos. Así, la dimensión de la búsqueda debe propiciarse desde el favorecer preguntas donde los jóvenes se sientan interpelados y de esta manera descubran nuevas respuestas que suscitan otras. De allí que la teología transversal se construya en gerundio, pues no se plantea como verdades estáticas sino como misterios que se descubren.

Por su parte, la dimensión interreligiosa tiene su constatación práctica en el aula cuando las temáticas no se presentan solo desde una visión, sino que se muestran como un abanico de creencias, donde todas enriquecen la realidad que se está estudiando. Se trata, por tanto, de deconstruir la hegemonía y plantearse el reconocimiento de las singularidades que sitúe a los creyentes y no creyentes en una relación de equiparidad de derechos.

La teología transversal se fundamenta en una antropodiversidad, de modo que las afirmaciones de la antropología teológica clásica sean interpeladas por otras antropologías que respondan de mejor manera al misterio del ser humano, y así valorarlo en su otredad. Al respecto, es necesario dejar atrás esquemas de uniformidad y pasar a considerar, imperiosamente, la perspectiva de género, el cuerpo, la ecología y los nuevos contextos, entre otras. 
A su vez, este tipo de teología es interdisciplinar. Los avances que los teólogos están haciendo deben llegar al aula para que los estudiantes puedan descubrir lenguajes comunes y, de esa manera, hacer la relación entre fe y cultura, fe y ciencia, fe y arte, fe y deporte, entre otras.

Finalmente, la teología transversal es trascendente y ética, considerando que los jóvenes buscan un sentido a sus profesiones que vaya más allá de ser una pieza del sistema económico imperante. Este deseo de bien común y justicia se debe desplegar en temas de la teología transversal, la cual necesita concretar sus reflexiones en la búsqueda del bien de la humanidad.

Finalmente, es preciso señalar que la teología transversal surge desde los contextos universitarios, donde los jóvenes son el lugar teológico principal. Esto no quiere decir que esta teología no se pudiese aplicar a otros contextos como mujeres, culturas, pueblos originarios, entre otros. Desde aquí, el desafío de una nueva narrativa teológica que se realiza con los jóvenes creyentes y no creyentes, posibilitando que toda experiencia de Dios y del ser humano sea valorada.

\section{Referencias}

Adimark (2017). Encuesta nacional Bicentenario 2017. Pontificia Universidad Católica de Chile. Recuperado de https:// encuestabicentenario.uc.cl/wp-content/uploads/2017/10/UC-Gfk-ADIMARK_Religio\%CC\%81n.pdf

Aguiló, A. (2010). Hermenéutica diatópica, localismos globalizados y nuevos imperialismos culturales: orientaciones para el diálogo intercultural. Cuadernos Interculturales Universidad de Valparaíso, 14(8), pp.145-163.

Aros, J. (2016). Una lectura de la misión de la universidad católica desde el prisma de la trascendencia del hombre en el pensamiento de Karl Rahner. Franciscanum, 58(166), pp. 179- 215.

Arteaga, A. (2002). Teología en la Universidad. Teología y vida, 43(1), 05-20. https://dx.doi.org/10.4067/S004934492002000100002

Barahona, P. (2015). Aprendizaje de la bioética en el contexto universitario: una propuesta metodológica desde la visión cristiana. Innovación y transversalidad en el Plan Común Universidad, (pp. 195-221). Santiago de Chile: UCSH.

Basualto L. (2015). Educar en derechos humanos a través del método inductivo: ver, juzgar y actuar. Innovación y transversalidad en el Plan Común Universidad, (pp. 173-193). Santiago de Chile: UCSH.

Brito, S. y Basualto, L. (2018). El académico como formador integral de juventudes en un mundo complejo. Un desafio personal, social y trascendente. Juventud (es) y jóvenes; perspectivas desde la formación integral UCSH. Experiencias académicas desde diversos espacios formativos. Santiago de Chile: UCSH.

Brito, S. y Reyes, L. (2017). Hacia un currículum basado en competencias. Formación transversal y competencias genéricas en universidades (pp. 209-221). Santiago de Chile: UCSH.

Centro de Formación Teológica. (2014). Enfoque educativo del Centro de Formación teológica. Bogotá: Pontificia Universidad Javeriana, Facultad de Teología. Recuperado de:https:/teologia.javeriana.edu.co/documents/3722978/3785760/ CFT+El+enfoque+educativo+del+CFT.pdf/da1336dd-e551-4b41-ac14-3bbe27559543

CEP (2018). Tema especial. Religión. Recuperado de https:/www.cepchile.cl/cep/site/artic/20181218/ asocfile/20181218093906/encuestacep_oct_nov2018_te_religion.pdf 
Comisión Nacional de Pastoral Juvenil (2018).

Farías, M. (2016). La antropología teológica en el Plan Común Universidad. Desde la pedagogía del descubrimiento a la praxis innovadora. Reflexiones de los docentes del Plan común universidad (pp. 127-151). Santiago, Chile: UCSH.

Fornet-Betancourt, R. (2006). La interculturalidad a prueba. Recuperado de: http://www.uca.edu.sv/filosofia/admin/ files/1210106845.pdf

Francisco (2018a). Al pueblo de Dios que peregrina en Chile. Recuperado de http://w2.vatican.va/content/francesco/ es/letters/2018/documents/papa-francesco_20180531_lettera-popolodidio-cile.html

Francisco (2018b). Gaudate et exsultate. Santiago de Chile: San Pablo.

Francisco (2019). Christus vivit. Santiago de Chile: San Pablo.

González, C. y Basualto, L. (2019). Hacia una pastoral con jóvenes para-institucionales. Revista de Educación religiosa, 1(2), 9-36.

González de Cardedal, O. (2016). Ciudadanía y cristianía. Una lectura de nuestro tiempo. Madrid: Encuentro.

INE (2012). Censo 2012. Recuperado de: estudios.anda.cl/recursos/censo_2012.pdf

INJUV (2015). Octava Encuesta nacional de la Juventud 2015. Santiago de Chile: Injuv.

Latinobarómetro (2018). El Papa Francisco y la religión en Chile y América Latina. Recuperado de https://www. cooperativa.cl/noticias/site/artic/20180112/asocfile/20180112124342/f00006494_religion_chile_america_ latina_2017.pdf

Muñoz, D. (2016). Educar en derechos humanos a través de la pedagogía de la memoria. Desde la pedagogía del descubrimiento a la praxis innovadora. Reflexiones de los docentes del Plan común universidad (pp. 207-225). Santiago de Chile: UCSH.

Muñoz, D. y Basualto, L. (2017). Evaluación y sistematización PFI Eje 2, Teología y sociedad. Cristianismo y hecho religioso. Segundo semestre 2016. Informe entregado a la Dirección de Docencia UCSH.

Sínodo de los Obispos (2018a). Los jóvenes, la fe y el discernimiento vocacional, Instrumentum laboris. Ciudad del Vaticano. Recuperado de http://www.synod2018.va/content/synod2018/es/documentos/instrumentumlaboris-para-el-sinodo-sobre-los-jovenes-2018.html

Sínodo de los Obispos (2018b). Documento Final de la XV Asamblea General Ordinaria: Los jóvenes, la fe y el discernimiento vocacional. Recuperado de http://www.vatican.va/roman_curia/synod/documents/rc_synod_ doc_20181027_doc-final-instrumentum-xvassemblea-giovani_sp.html

UCSH (2016). Plan de Formación Integral. Santiago de Chile: UCSH.UCSH (2017). Guía procedimental. Competencias genéricas UCSH 2017. Santiago de Chile: UCSH.

UCSH (2018). Informe descriptivo, caracterización del estudiante del primer año 2018. Santiago de Chile: UCSH. 